\title{
Drinking motives, alcohol expectancies, self-efficacy, and drinking patterns
}

Citation for published version (APA):

Engels, R., Wiers, R. W. H. J., Lemmers, L., \& Overbeek, G. (2005). Drinking motives, alcohol expectancies, self-efficacy, and drinking patterns. Journal of Drug Education, 35(2), 147-166. https://doi.org/10.2190/6Q6B-3LMA-VMVA-L312

Document status and date:

Published: 01/01/2005

DOI:

10.2190/6Q6B-3LMA-VMVA-L312

Document Version:

Publisher's PDF, also known as Version of record

\section{Please check the document version of this publication:}

- A submitted manuscript is the version of the article upon submission and before peer-review. There can be important differences between the submitted version and the official published version of record.

People interested in the research are advised to contact the author for the final version of the publication, or visit the DOI to the publisher's website.

- The final author version and the galley proof are versions of the publication after peer review.

- The final published version features the final layout of the paper including the volume, issue and page numbers.

Link to publication

\footnotetext{
General rights rights.

- You may freely distribute the URL identifying the publication in the public portal. please follow below link for the End User Agreement:

www.umlib.nl/taverne-license

Take down policy

If you believe that this document breaches copyright please contact us at:

repository@maastrichtuniversity.nl

providing details and we will investigate your claim.
}

Copyright and moral rights for the publications made accessible in the public portal are retained by the authors and/or other copyright owners and it is a condition of accessing publications that users recognise and abide by the legal requirements associated with these

- Users may download and print one copy of any publication from the public portal for the purpose of private study or research.

- You may not further distribute the material or use it for any profit-making activity or commercial gain

If the publication is distributed under the terms of Article $25 \mathrm{fa}$ of the Dutch Copyright Act, indicated by the "Taverne" license above, 
+J. DRUG EDUCATION, Vol. 35(2) 147-166, 2005

\title{
DRINKING MOTIVES, ALCOHOL EXPECTANCIES, SELF-EFFICACY, AND DRINKING PATTERNS*
}

RUTGER C. M. E. ENGELS

Radboud University Nijmegen, The Netherlands

REINOUT WIERS

Maastricht University, The Netherlands

LEX LEMMERS

Trimbos Institute, Utrecht, The Netherlands

GEERTJAN OVERBEEK

Radboud University Nijmegen, The Netherlands

\begin{abstract}
The current study focused on the associations between drinking motives, alcohol expectancies, self-efficacy, and drinking behavior in a representative sample of 553 Dutch adolescents and adults. Data were gathered by means of self-report questionnaires and a 14-days drinking diary. A model was postulated in which negative expectancies and self-efficacy were directly associated with drinking, and in which drinking motives mediated the associations between positive expectancies, and drinking. The findings of multivariate analyses showed that drinking motives were related to general indicators of drinking and to drinking levels in specific situations. Furthermore, self-efficacy was moderately related to all drinking variables. Negative expectancies were related to general drinking variables but hardly to drinking
\end{abstract}

*This research was supported by a grant of the Netherlands Institute for Health Promotion and Disease Prevention. Rutger Engels was supported by a fellowship of the Dutch Organization of Scientific Research during the preparation of this manuscript.

147

(C) 2005, Baywood Publishing Co., Inc. 
in specific situations. Positive expectancies were hardly related to drinking in multivariate analyses and therefore mediation models could not be tested. No systematic moderator effects were apparent for age and gender on the associations between drinking motives, alcohol expectancies, self-efficacy, and drinking.

In the early nineties, Stacy, Newcomb, and Bentler (1991) argued that people's cognitive motivation to engage in behaviors, such as drinking, drug use or smoking, is a key factor in theories on health-related behaviors. Expectancies about the perceived consequences of actions are expected to affect whether people start to drink, become regular users, or become addicted to alcohol and to develop alcohol related problems. Cooper and colleagues (Cooper, 1994; Cooper, Frone, Russell, \& Mudar, 1995) suggested that for an adequate understanding of the development of drinking patterns, knowledge on psychological motives to consume alcohol might be essential. In line with the work of Cox and Klinger (1988), they argued that drinking motives are distinctively different from alcohol expectancies, and that drinking motives are the most proximal factors (see Cooper, 1994). In the current study, we examined the associations between drinking motives, alcohol expectancies, self-efficacy, and alcohol consumption in a study of 553 regular drinkers.

Research on alcohol expectancies has become central in theoretical models explaining adolescent and adult involvement in drinking patterns, alcohol misuse and alcohol-related problems (Abrams \& Niaura, 1987; Leigh, 1989). Since Brown, Goldman, Inn, and Anderson (1980) developed the Alcohol Expectancy Questionnaire (AEQ) assessing individual perceptions of positive alcohol related consequences, many studies have been conducted to assess alcohol expectancies (see also George, Frone, Cooper, Russell, Skinner, \& Windle, 1995; Goldman, Del Boca \& Darkes, 1999; Leigh \& Stacy, 1993). The empirical evidence for the efficacy of alcohol expectancies to explain variation in drinking patterns is quite substantial in cross-sectional studies. Studies among adolescents (e.g., Christiansen \& Goldman, 1983; Wiers, Hoogeveen, Sergeant, \& Gunning, 1997) and adults (e.g., Cooper, Russell, \& George, 1988) found support for moderate to strong associations between alcohol expectancies and drinking. Contrasting findings have been reported in studies concerning the effects of alcohol expectancies on changes in alcohol consumption over time. Some studies found moderate associations between expectancies and drinking over a 1-year period (Goldman, Greenbaum, \& Darkes, 1997) whereas other reported that alcohol expectancies were related to specific stages of drinking (e.g., onset of drinking; Aas, Leigh, Anderssen, \& Jakobsen, 1998), to specific drinking habits (e.g., alcohol-related consequences but not to alcohol use; Reese, Chassin, \& Molina, 1994), and only marginally to drinking in young adults (e.g., Sher, Wood, 
Wood, \& Raskin, 1996; Stacy, Newcomb, \& Bentler, 1991). A few prospective studies found no effect of alcohol expectancies on changes in drinking over time (e.g., Johnson, 1988; see also discussion in Jones, Corbin, \& Fromme, 2001; Sher et al., 1996).

According to Bandura (1995), self-efficacy has been a central issue in explanatory models of addictive behaviors. He defined self-efficacy as the "beliefs in one's capabilities to organize and execute the courses of action required to manage prospective situations" (p. 2). In the application of self-efficacy theory in the field of addiction, it is assumed that successful coping in a variety of high-risk situations increases perceived self-efficacy (e.g., Epstein, Griffin, \& Botvin, 2000; Grunbaum, Tortolero, Weller, \& Gingiss, 2000). Further, some studies have examined the associations between alcohol expectancies, and selfefficacy on the one hand, and drinking measures on the other hand. For instance, in a cross-sectional study of 359 college students, Connor, Young, Williams, and Ricciardelli (2000) found that both alcohol expectancies and drinking refusal self-efficacy uniquely contributed to the prediction of alcohol problems (see also Evans, \& Dunn, 1995; Lee, Oei, \& Greeley, 1999).

Several scholars have argued that people's drinking behavior is strongly affected by the motivations for drinking they endorse. Cox and Klinger (1988) proposed a framework in which motives are characterized by two dimensions reflecting the valence (positive or negative) and the source (internal and external) (Cooper, 1994). This framework results in four types of motives: drinking to obtain social rewards, drinking to enhance positive mood, drinking to deal with negative emotions, and drinking to avoid social rejection. Cooper and colleagues (Cooper, 1994; Cooper et al., 1995) found support for the validity of the 4-factor structure of their measurement of drinking motives using confirmatory factor analyses, and the differential associations of drinking motives with alcohol use. For instance, they found that social and enhancement motives were related to heavy drinking, to drinking in situations in which heavy drinking is tolerated, and to drinking at parties. In contrast, drinking to regulate negative emotions and problems was related to solitary drinking, and not to drinking in social situations, such as pubs and bars (Cooper, 1994: see also Mohr, Armeli, Tennen, Carneg, Affleck, \& Hromi, 2001). In sum, there is preliminary evidence that different drinking motives are affecting different drinking habits in both adolescents and adults.

Furthermore, Cooper et al. (1995) suggested that drinking motives may mediate some of the associations between alcohol expectancies and drinking behavior. This argues for a theoretical model (see Figure 1), in which the expectancies about the positive effects of drinking (e.g., social, sexual or tension reduction) are indirectly related to drinking behavior, by their effect on drinking motives. In addition, it is assumed that expectancies about the negative effects of drinking are not related to drinking motives, but directly affect drinking behavior. 
Therefore, in the current article, we focus on the direct and indirect role of drinking motives, alcohol expectancies, and self-efficacy in the explanation of differences in drinking behavior.

In most cases, researchers employ general frequency and intensity measures or measures of heavy drinking and drinking problems. The first concern with respect to these assessments is that in cross-sectional designs, in essence, one predicts earlier drinking habits from later responses on alcohol expectancies, drinking motives or self-efficacy because most drinking variables refer to previous drinking habits whereas the assessment of drinking cognitions refer to current ideas, opinions and feelings. A second point of concern is related to the reliability of drinking measures. Instead of using rough measures of annual frequency or intensity of alcohol consumption, it is preferable to employ more reliable assessments of drinking habits, such as observational methods (e.g., Bot, Engels, \& Knibbe, in press), the timeline follow back method (e.g., Sobell \& Sobell, 1992), collateral reports (for instance by friends, see Stacy, Widaman, \& Marlatt, 1990), or diary data (e.g., Lemmens, Tan, \& Knibbe, 1992).

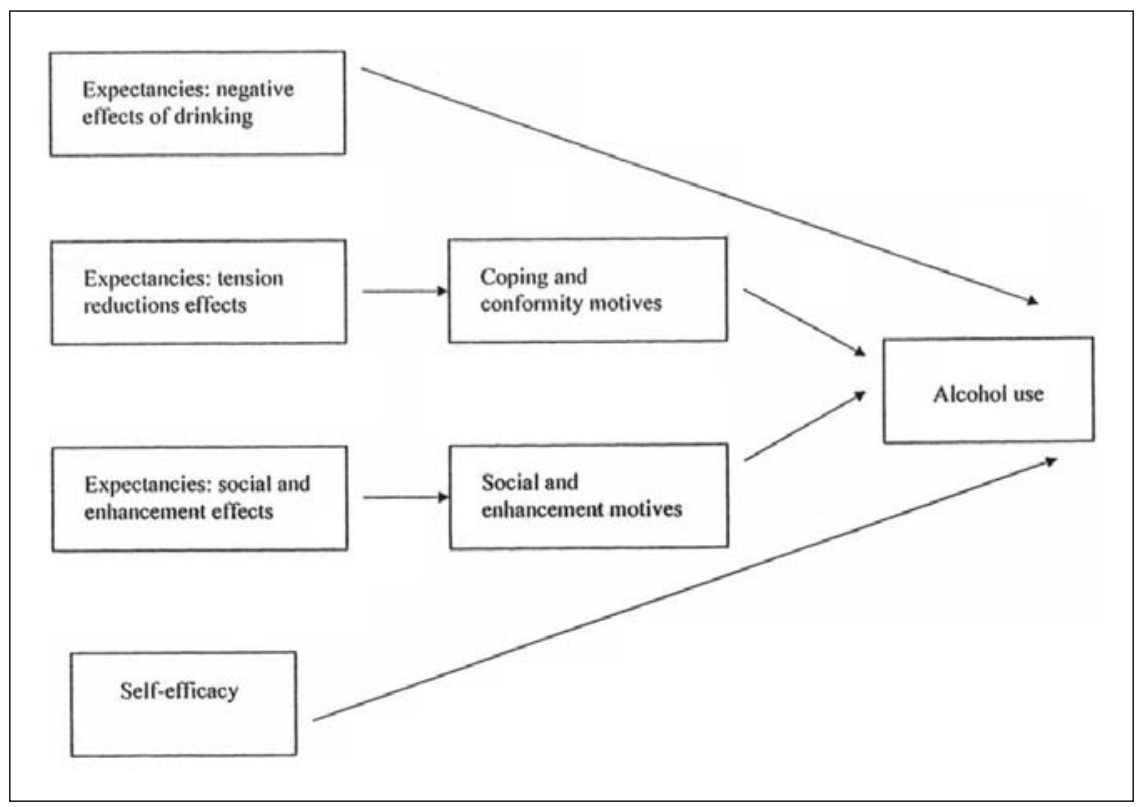

Figure 1. Theoretical model concerning the relationships between drinking motives, alcohol expectancies, self-efficacy, and drinking behavior. 
The current study examines the associations between drinking motives, alcohol expectancies and self-efficacy and drinking measures in a study of 553 regular drinkers. Data were gathered by means of (a) self-report questionnaires including general drinking measures, drinking motives, alcohol expectancies, and self-efficacy and (b) a drinking diary in which respondents had to fill out their alcohol consumption in various situations for a period of two weeks. We tested whether, as Cooper et al. (1995) found, specific motives mediate the associations between positive expectancies and drinking levels in specific situations whereas negative expectancies and self-efficacy are directly related to consumption in specific drinking situations (Figure 1). Special attention has been paid to possible age and gender differences. We also examined possible moderator effects of age and gender on the associations between drinking cognitions and alcohol use.

\section{METHOD}

Data for analyses were derived from a study of 913 adolescents and adults carried out in 1997. A total of 672 participants were drawn from an existing national representative panel of 2400 households. Each member of this panel has a personal computer at home, and questionnaires were sent to respondents by e-mail. Because participation was restricted to only one person in a household, an additional number of 241 participants were added to the sample to hold representativeness. The participants in this group were visited by a research assistant at home and questionnaires were filled out on laptops. It is important to mention that although we strived for a representative sample, this does not imply that our sample is representative in terms of alcohol consumption. It is very likely that people with high consumption levels or alcohol-related problems are more likely to refrain from getting involved in research projects. With our data we can unfortunately not establish whether this happened to be the case.

After filling out the questionnaires, people who reported that they drank at least once a month in the past year were asked whether they would participate in the second phase of the study. A total of 553 persons ( $84 \%$ of the group that reported regular drinking) filled out a "drinking diary" every day for a period of two weeks. The administration of the diary took place directly after administration of the questionnaire. Further, participants were told that their responses would be handled strictly confidential. All participants agreed that we could use data for scientific purposes.

Those who are involved in the diary part of the study may differ from those who only filled out the questionnaire. Attrition analyses showed that the "diary sample" consisted of more males (58\% was male compared to $41 \%$ in the "questionnaire only sample"). No differences were found on age and educational level. We only used data from the subset of respondents who had provided 
complete data on both the questionnaire and diary parts. A total of 324 men and 229 women were included in this subset. The mean age was $42.17(S D=18.4)$. Because we examined models for different age groups, we divided the sample into 3 subgroups of respondents: 154 (28\%) respondents were between 15 and 29 years of age (young adult group), 267 (48\%) respondents between 30 and 55 (middle aged group), and 132 (24\%) respondents older than 55 (older age group). Concerning educational level, $26 \%$ were lower educated, $34 \%$ middle educated and $40 \%$ higher educated.

\section{Measures}

\section{Alcohol Consumption: Questionnaire}

Three assessments of alcohol use were employed. First, people were asked to report the frequency of drinking in the past 12 months in 8 situations (i.e., at a pub or disco, at a party, at day time with friends or relatives, after sports, at a restaurant, at dinner at home, alone at home and during visits of friends or relatives). Responses ranged from 1 "never" to 8 "always." The responses were summed to an index of the frequency of drinking. Second, the frequency of heavy drinking was measured by asking respondents to indicate how often they drank 5 or more glasses per occasion in the past 12 months. Responses ranged from 1 "not a single day" to 8 "(almost) every day." Third, the level of consumption in the past week was assessed by asking the number of glasses respondents consumed for each day of the past 7 days. For these 7 items, responses ranged from 1 "0 glasses" to 11 "more than 20 glasses" (see Hajema, 1998).

\section{Alcohol Consumption: Diary}

For a period of two weeks, people had to indicate the number of glasses they consumed. First, respondents were asked whether a specific situation occurred that day: being at a pub or disco, being at a party, spending daytime with friends or relatives, engagement in sports, being at a restaurant, having dinner at home, being alone at home and having visits of friends or relatives. In the case they indicated that the situation occurred, they were asked the number of glasses they consumed in that situation with an open-answer format. Because these 8 situations of course do not cover all possible drinking situations, we also asked respondents each day to provide the total number of glasses they consumed that specific day. To prevent people to guide recollection of the responses by the responses on the 8 situations, this general question was asked first. The responses on the 8 situations covered $78 \%$ of the total consumption of these 2 weeks. Variables were constructed by summing the level of alcohol consumption in the 8 situations for a period of 14 days. We focused here on 
drinking levels in 5 situations: alone at home, dinner at home, public drinking places, parties, and during visits from relatives or friends. Too few persons provided data on drinking in the other three settings to conduct adequate multivariate analyses.

The reliability of assessments through this drinking diary may be less affected by memory distortions than the questionnaire data (Lemmens et al., 1992). Nevertheless, such detailed assessments of drinking habits may have a preventive effect on individuals drinking habits because people become very conscious of their drinking. We checked this by examining whether respondents reported lower drinking levels in the first week compared to the second week. This was not the case.

\section{Motives for Drinking}

Drinking motives were measured by the 20 -item questionnaire developed by Cooper (1994, see also Cooper et al., 1995). She assessed four types of motives: drinking to obtain social rewards, drinking to enhance positive mood, drinking to deal with negative emotions, and drinking to avoid social rejection. Each of the motives consists of 5 items with responses ranging from 1 "never" to 7 "always." Internal consistencies of the subscales ranged from .82 to .88 . Because of the high intercorrelations between social and enhancement (positive reinforcement) motives and coping and conformity (negative reinforcement) motives, we combined these scales into two factors.

\section{Alcohol Expectancies}

An adaptation of the Alcohol Expectancy Questionnaire (AEQ; see Brown et al., 1980) was used. George et al. (1995) conducted confirmatory factor analyses on the 40-item AEQ-2 in a sample of 1260 adults, and found an 8 factor structure. The subscales are: Global positive ( 5 items), social and physical pleasing (5 items), social expressiveness ( 5 items), sexual enhancement (5 items), power and aggression (6 items), tension reduction and relaxation ( 5 items), cognitive and physical impairment (5 items) and careless concern (4 items) (7-points scale ranging from 1 "totally disagree "to 7 "totally agree").

Wiers and colleagues $(1997,1998,2000)$ argue for the assessment of doserelated alcohol expectancies. We asked respondents to fill out the George et al. (1995) version of the AEQ (version 3) twice: one time for the expectancies about the effects of drinking 1 or 2 glasses per occasion, and one time for the expectancies about the effects of drinking 5 or more glasses per occasion. The internal consistencies for the 16 scales ranged from .67 to .91 .

We followed the suggestions of George et al. (1995) not to use the separate subscales in multivariate analyses due to the high interrelations between the subscales. They suggest to construct two factors: positive and negative 
expectancies. Because we concentrate on the relationships between expectancies and corresponding motives, we decided to divide the positive expectancies in two groups: expectancies about the positive social, sexual and enhancement effects and expectancies about the tension reduction and relaxation effects of drinking. Because we used two forms of the AEQ-3; one for the expectancies on drinking 1 or 2 glasses and one for the expectancies of drinking 5 or more glasses, it was examined if these two forms should be combined, or should be treated as different constructs in analyses. The Pearson correlations between the scales of the two versions were high, ranging from .76 to .85 , all $p<.001$. Therefore, we decided to combine both forms into three variables; positive expectancies regarding the social and enhancement effects of drinking, positive expectancies regarding the tension reduction effects of drinking, and negative expectancies.

\section{Self-Efficacy}

Self-efficacy was defined as the respondent's ability to quit drinking after having a maximum of 2 drinks. Respondents had to indicate for 11 situations how easy or difficult they would find it to quit after having 2 drinks. These situations were derived from studies by Aas, Klepp, Laberg, and Edvard (1995); De Vries, Dijkstra, and Kuhlman (1988); and Young, Oei, and Crook (1991). Examples of situations are "being with friends who drink alcohol," "being at a party," "feeling sad," and "being alone at home in the evening." Responses ranged from 1 "absolutely not" to 7 "absolutely yes." Internal consistency was high, namely $\alpha=.91$.

\section{RESULTS}

\section{Descriptive Analyses}

Table 1 shows the means and standard deviations of the variables. Concerning drinking motives, it appeared that people more often mentioned to drink because of social and enhancement motives than of coping or conformity motives. Furthermore, moderate scores on alcohol expectancies were reported, whereas high scores were obtained for self-efficacy: most respondents indicated to be confident about their ability to quit drinking after having 2 glasses. Concerning drinking behavior, only a small percentage of the respondents reported to drink heavily very often. Mean weekly consumption was 10.6 glasses. With respect to drinking settings, highest levels were reported on drinking in pubs and discos and at parties and lowest levels alone at home and at dinner. 
Table 1. Means and SDs for Model Variables

\begin{tabular}{|c|c|c|c|}
\hline & Mean & $S D$ & Range \\
\hline Mot - soc-enh & 3.13 & 1.34 & $1-7$ \\
\hline Mot - cop-conf & 1.67 & .88 & $1-7$ \\
\hline Exp - pro social & 2.89 & .94 & $1-5.81$ \\
\hline Exp - pro tension & 3.86 & 1.19 & $1-7$ \\
\hline Exp - neg & 3.39 & 1.09 & $1-7$ \\
\hline Self-efficacy & 6.10 & 1.03 & $1-7$ \\
\hline Frequency of drinking & 4.30 & 1.26 & $1.38-8$ \\
\hline Frequency of heavy drinking & 2.67 & 1.68 & $1-7$ \\
\hline Intensity of drinking & 10.64 & 11.01 & $0-50$ \\
\hline \multicolumn{4}{|l|}{ Drinking } \\
\hline alone at home & 2.09 & 1.60 & .10-9 \\
\hline at dinner & 1.57 & .68 & $.10-9$ \\
\hline at bars, discos & 5.11 & 4.07 & $.40-19$ \\
\hline at parties & 4.17 & 3.63 & $.10-25.5$ \\
\hline at visits & 2.88 & 2.44 & .40-20 \\
\hline
\end{tabular}

Intercorrelations between Drinking Motives, Alcohol Expectancies, Self-Efficacy, and Drinking Behavior

Pearson correlations showed that people's motives for drinking are interrelated. People who indicated drinking for social or enhancement reasons were more likely to drink for coping or conformity reasons (Table 2). In addition, drinking motives were moderately positively related to expectancies concerning the positive effects of drinking and negative effects of drinking, and negatively to self-efficacy. Drinking motives were positively associated with general drinking measures and with drinking in different settings. Nonetheless, drinking motives were not related to quantity of drinking at dinner and alone at home (only non-significant for coping conformity motives). 


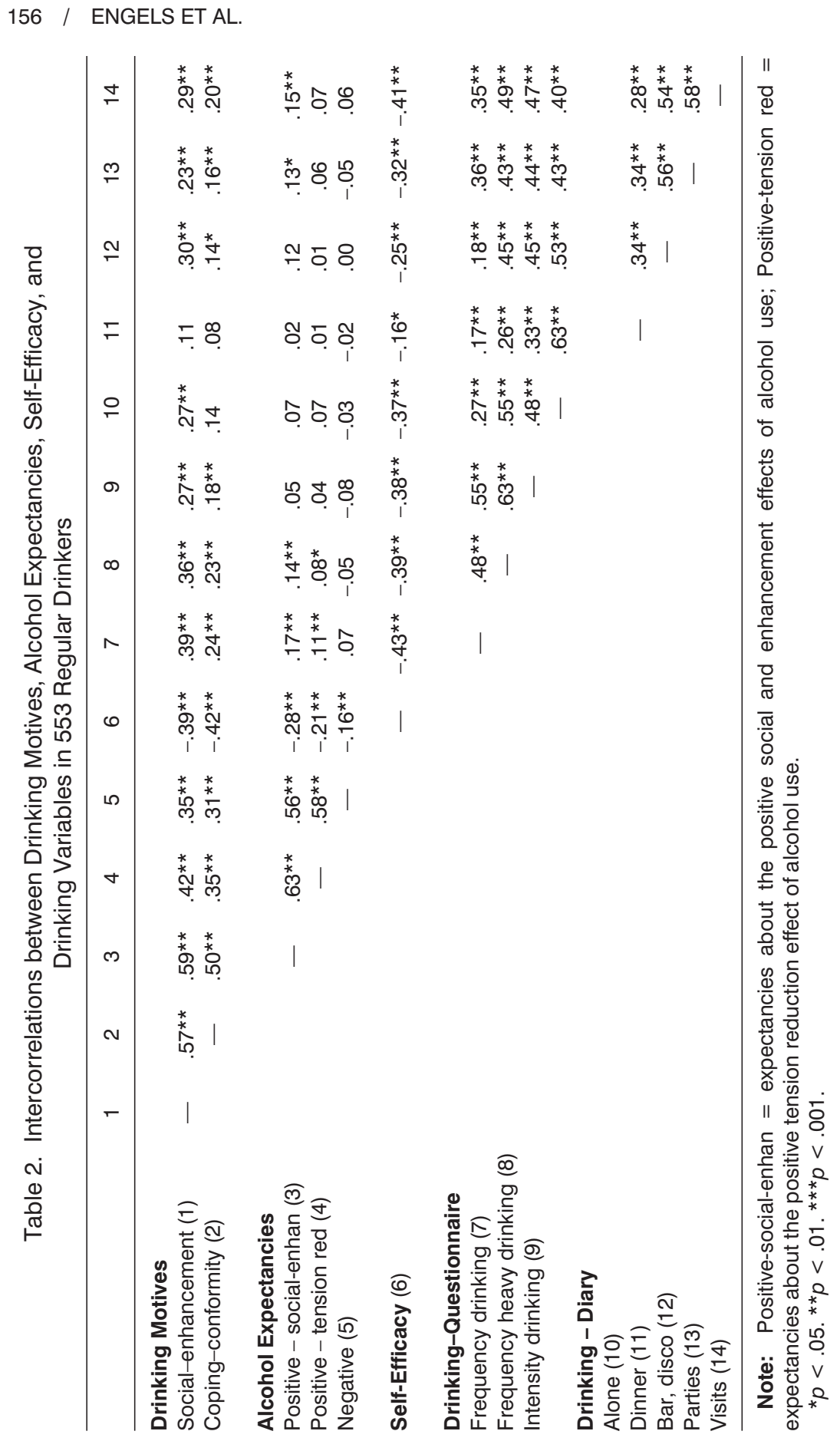


Positive outcome expectancies were related to frequency of drinking and heavy drinking and not to quantity of drinking. In addition, positive expectancies were hardly related to the level of drinking in specific settings. Only social and enhancement expectancies were related to drinking at parties and at visits. Expectancies about the negative effects of drinking were related neither to general indicators of drinking nor to drinking in specific settings. In addition, the three positive and negative expectancies scales are strongly positively interrelated. Self-efficacy was related to the expectancy scales and to all drinking measures.

\section{Associations between Drinking Motives, Alcohol Expectancies, and Self-Efficacy and Three Assessments of Alcohol Consumption: Questionnaire Data}

The first step in testing mediating links is to verify whether independent, mediator and dependent variables are significantly associated on the univariate level (Baron \& Kenny, 1986). With respect to the general indicators of drinking, this assumption was fulfilled. Only concerning the associations with intensity of drinking, none of the three expectancy scales were not related to drinking, so no mediation could be tested in this particular case.

Table 3 shows the results of multivariate regression analyses in which direct and indirect links were examined. It appeared that expectancies about the positive effects of drinking were hardly related to drinking (see also univariate correlations depicted in Table 2). Self-efficacy was strongly related to drinking measures in all analyses. In the second step, after drinking motives entered the equation, it appeared that in none of the cases positive expectancies were related to drinking. Mediation could not be tested with respect to frequency and intensity of drinking. Concerning frequency of binge drinking, it appeared that the small direct effect of positive expectancies on drinking disappeared after controlling for smoking motives.

Additional analyses were conducted to examine possible interaction effects of age and gender by conducting hierarchical regression analyses with drinking motives, alcohol expectancies, self-efficacy and age (or gender) as a block in step 1, and interaction terms (drinking motives/self-efficacy/alcohol expectancies* age/gender) as a block in step 2 (not in Tables). Age was categorized in three groups: 18-29-year olds, 30-55-year-olds, and $>55$-year-olds. Only one of the 6 blocks of interactions was significant at $p<.05$. This concerned the interaction between age and self-efficacy in predicting frequency of heavy drinking. It appeared that the association between self-efficacy and frequency of heavy drinking was stronger for older respondents $(\beta=-.45, p<.01)$ than for middle aged respondents $(\beta=-.29, p<.01)$ and young respondents $(\beta=-.16$, $p<.05)$. 
Table 3. Multiple Regression Analyses Predicting Drinking by Drinking Motives, Alcohol Expectancies, and Self-Efficacy:

Questionnaire Data

\begin{tabular}{ccc}
\hline Frequency & Frequency & Intensity \\
drinking last & heavy drinking & drinking \\
12 months & last 12 months & last week \\
\hline
\end{tabular}

\section{Step 1}

$\begin{array}{llcc}\text { Exp - pro social } & .08 & .11^{\star} & .01 \\ \text { Exp - pro tension } & -.01 & .06 & .06 \\ \text { Exp - neg } & -.04 & -.21^{\star *} & -.18^{\star *} \\ \text { Self-efficacy } & -.41^{\star *} & -.38^{* *} & -.40^{\star *} \\ R^{2} & .18^{* *} & .18^{* *} & .17^{\star *}\end{array}$

\section{Step 2}

$\begin{array}{llll}\text { Motives - soc-enh } & .34^{\star \star} & .33^{\star \star} & .25^{\star \star} \\ \text { Motives - cop-conf } & -.05 & -.01 & -.01 \\ \text { Exp - pro social } & -.07 & -.04 & -.11 \\ \text { Exp - pro tension } & -.02 & .04 & .04 \\ \text { Exp - neg } & -.04 & -.21^{\star \star} & -.18^{\star *} \\ \text { Self-efficacy } & -.34^{\star *} & -.30^{\star \star} & -.34^{\star *} \\ R^{2} & .25^{\star \star} & .24^{\star *} & .21^{\star *}\end{array}$

Note: Motives - soc-enh $=$ social and enhancement motives; motives - cop-conf $=$ coping and conformity motives; exp - pro social = expectancies about the positive social and enhancement effects of alcohol use; exp - pro tension = expectancies about the positive tension reduction effect of alcohol use; $\exp -$ neg $=$ expectancies about the negative effects of alcohol use.

$$
{ }^{*} p<.05 .{ }^{* *} p<.01 \text {. }
$$




\section{Associations between Drinking Motives, Alcohol Expectancies, and Self-Efficacy and Five Assessments of Alcohol Consumption: Questionnaire and Diary Data}

We aimed to test our theoretical model by looking at the total levels of drinking in 5 different settings in a two weeks period just after respondents had filled out questionnaires on drinking cognitions, such as motives, expectancies and self-efficacy.

Because the univariate analyses already showed no significant associations between the expectancies about the tension reduction aspects of drinking, the negative effects of drinking, and drinking levels in three specific settings (e.g., drinking alone, at dinner, and at parties), no mediational models could be tested. Only in the case of drinking at bars and discos, and visits of friends and relatives, mediation could occur. Therefore, concerning two drinking contexts we could test the hypothesized theoretical model whereas with respect to the other three drinking contexts we only provide the full model with no mediation tested.

Table 4 depicts the results of hierarchical regression analyses predicting drinking in 5 situations. Concerning alcohol use in public drinking places, drinking motives (e.g., social and enhancement) mediated the association between positive expectancies and drinking levels. No mediation was observed concerning drinking with visits of friends. In these analyses, direct associations between self-efficacy and drinking levels remained significant.

It appeared that social and enhancement motives were related to drinking in social situations, such as public drinking places and visits of friends, and to drinking alone at home. Coping and conformity motives were not multivariately related to drinking levels in these 5 situations. Alcohol expectancies concerning the positive and negative effects of drinking were hardly related to drinking habits in these multivariate analyses. Only 1 out of 15 parameters was significant: respondents who reported to expect negative consequences of their drinking were less likely to drink at parties. Self-efficacy predicted drinking levels in 4 out of 5 drinking variables. Respondents with low levels of selfefficacy were more likely to drink alone, at public drinking places, at parties, and by visits of friends or relatives.

Additional analyses were carried out to examine the possible moderator effects of age and gender. Concerning age and gender, none of the 10 blocks appeared to be significant (data not shown).

\section{DISCUSSION}

The current study aimed to examine the multivariate associations of drinking motives, alcohol expectancies, self-efficacy and alcohol use in a nationwide sample of Dutch adolescents and adults. 
160 / ENGELS ET AL.

Table 4. Multiple Regression Analyses Predicting Drinking in 5 Settings by Drinking Motives, Alcohol Expectancies, and Self-Efficacy: Questionnaire and Diary Data

\begin{tabular}{ccccc}
\hline Alone & Dinner & Bar, disco & Parties & Visits \\
$(n=168)$ & $(n=204)$ & $(n=206)$ & $(n=253)$ & $(n=294)$ \\
\hline
\end{tabular}

\section{Step 1}

$\begin{array}{llllll}\text { Exp - pro social } & - & - & .19^{*} & - & .08 \\ \text { Exp - pro tension } & - & - & -.03 & - & -.05 \\ \text { Exp - neg } & - & - & -.18^{*} & - & -.03 \\ \text { Self-efficacy } & - & - & -.24^{* *} & - & -.39 * * \\ R^{2} & - & - & .09^{* *} & - & .17^{\star *}\end{array}$

\section{Step 2}

\begin{tabular}{lccccc} 
Motives - soc-enh & $.28^{* *}$ & .12 & $.32^{\star *}$ & $.16^{*}$ & $.23^{* *}$ \\
Motives - cop-conf & -.10 & .01 & -.04 & .01 & -.01 \\
Exp - pro social & -.10 & -.04 & .05 & .08 & .01 \\
Exp - pro tension & .07 & -.03 & -.06 & -.01 & -.07 \\
Exp - neg & -.15 & -.06 & -.16 & $-.22^{* *}$ & -.05 \\
Self-efficacy & $-.34^{\star *}$ & -.14 & $-.20^{* *}$ & $-.27^{* *}$ & $-.35^{\star *}$ \\
$R^{2}$ & $.19^{* *}$ & .04 & $.15^{\star *}$ & $.15^{\star *}$ & $.20^{\star *}$ \\
\hline${ }^{*} p<.05 .{ }^{* *} p<.01$. & & & & &
\end{tabular}

First of all, social and enhancement motives were most frequently mentioned as reasons for consuming alcohol compared to coping and conformity motives. These findings are in line with Cooper et al. (1995) and Stewart, Zeitlin, and Samoluk (1996). Coping and conformity reasons for drinking do not seem to be prominent issues, at least in the eyes of the beholder. Additionally, it should be stressed that the intercorrelations between the four motives were moderately 
to high, ranging from .40 to .67 . In our opinion, it is noteworthy that coping motives are positively related to social and enhancement motives (see Cooper et al., 1995). Thus, people who drink to deal with personal problems also report drinking for social reasons.

Moreover, we aimed to test a theoretical model (see Cooper et al., 1995) in which drinking motives, self-efficacy and expectancies about the negative effects of drinking were directly related to drinking variables, and drinking motives would act as a mediator between the associations between expectancies about the positive effects of drinking and drinking variables. However, although we found some support for the direct links between social and enhancement motives, negative expectancies, self-efficacy, and drinking, no support was found for a mediating role of drinking motives.

Alcohol expectancies, drinking motives and self-efficacy accounted for more variance in the prediction of general drinking measures $\left(r^{2}\right.$ s between .21 and .25) than in the prediction of situational drinking $\left(r^{2}\right.$ s between .04 and .19). This surprising us, because we expected that more accurate and specific assessments of drinking would result in stronger predictions. General drinking measures do not provide insight into type of drinking company, time of day or type of setting, and therefore may be more difficult to predict. George et al. (1995) argued that the theoretical value of alcohol expectancies would be enhanced if empirical studies demonstrate that specific expectancies are linked to specific drinking habits. Our data on drinking motives and levels of drinking in various situations partly support this assumption. Social and enhancement motives were multivariately associated with drinking in social settings, such as pubs, discos and parties, and at home. We conducted additional analyses to test whether the relationship of social and enhancement motives and drinking at home could be explained by enhancement motives rather than by social motives and this appeared to be the case (see also Cooper, 1994). However, no clear differentiated links between coping and conformity motives, and drinking were found. There are several explanations. First, the rather global assessment of these drinking motives may also account for these findings. Perhaps if, for instance, enhancement motives were more specifically assessed stronger associations with drinking in specific settings would be found. Second, perhaps if we distinguished groups of people who restrain their drinking to very specific settings, for example, only at home and not at parties or in public drinking places, we would find stronger links between certain motives and drinking habits. However, the small size of the subsamples makes it difficult to focus on motives of people who only drink in specific settings. Finally, it should be said that although it is possible to employ all subscales of the alcohol expectancies questionnaire to look at differential associations with drinking in specific situations, the high intercorrelations between the subscales of the AEQ make it difficult to conduct multivariate analyses in which the different aspects of alcohol expectancies would appear to 
be related to specific drinking patterns (George et al., 1995). Further, one might argue that motives and expectancies strongly overlap. For instance, concerning social enhancement, people could perceive motives and expectancies as being similar. There is however no empirical evidence for this assumption; the correlation between motives and expectancies concerning social enhancement is moderate, indicating that motives and expectancies are distinguishable constructs (see also Cooper et al., 1995).

Alcohol expectancies were not strongly related to alcohol use which may seem in contrast with some other studies (e.g., George et al., 1995; Goldman et al., 1997; Leigh, 1989; Wiers et al., 1997). Because we employed an instrument that is widely employed in the area of alcohol expectancies, the AEQ (e.g., Brown, Christiansen, \& Goldman, 1987) and recently adapted by George et al. (1995), we do not think that the assessment of expectancies as such accounts for these findings. It is possible that the assessment of drinking by diaries in our study, the inclusion of only regular drinkers, and the fact that primarily adults were included in the study (mean age was 42) are part of the explanation for the small associations of alcohol expectancies with drinking variables shown in the sample. We also conducted some additional analyses (data not shown) in which we controlled for previous drinking behavior in the prediction of the levels of drinking behavior in the five drinking contexts and which may be seen as short-term prospective analyses. The outcomes showed that after controlling for previous drinking, drinking cognitions could hardly predict drinking levels (explained variances of motives, expectancies and self-efficacy ranged from between .01 and .04). Sher et al. (1996) discussed the problem of how to interpret estimates of the associations between expectancies and alcohol use in light of the various intervals between the waves in prospective studies. More specifically, they found hardly any effects of expectancies on drinking in a 4-wave design with 12-months intervals, but found a significant effect of expectancies on drinking over a period of 3 years. In other words, the longer the intervals between the waves, the stronger were the effects. Their explanation for these findings is that especially in adulthood, there is a strong stability of drinking over time, which implies that most of the variance in future alcohol use is accounted for by earlier alcohol use. It also implies that particularly in adults, neither alcohol expectancies, drinking motives nor self-efficacy add much to the explanation of drinking use because drinking is quite habitual (e.g., Goldman et al., 1999; Jones et al., 2001). Primarily among people who undergo substantial transitions in social status (Hajema, 1998) or drinking behavior, for instance, adolescents who start to drink (Smith, Goldman, Greenbaum, \& Christiansen, 1995), or late adolescents who go to college or university and increase their drinking levels substantially (e.g., Wechsler, Dowdall, Maenner, Gledhill-Hoyt, \& Lee, 1998), it may be more relevant to study the effects of alcohol expectancies on drinking behavior. 
The strengths of the current study lie in the use of a representative sample of Dutch adolescents and adults instead of using student samples which is done in the majority of studies, the possibility of examining the associations between drinking motives, alcohol expectancies, self-efficacy, and alcohol use in one single study, and the quality of assessment of alcohol use by employing both questionnaire and diary methods. Nevertheless, our study suffers from several shortcomings. First, it should be stressed that longitudinal research with more than two waves and substantial intervals between the waves is warranted to allow more definite conclusions regarding the effects of drinking cognitions on drinking behavior. Second, the emphasis on measurement of drinking behavior requires the need to include other assessments of drinking besides self-reports in questionnaires and diaries, such as observational methods and collateral reports by friends, parents, or a partner. Third, to look at the prediction of changes in alcohol use it is necessary to obtain variance in drinking measure. In particular studies with large samples provide the opportunity to examine predictors of substantial increases and decreases in drinking. A related advantage of increasing the power is that it allows analyses by subgroups in terms of gender, ethnicity, religion, age, and education.

In sum, the findings of the current study showed that (a) social and enhancement motives are related to general indicators of drinking and to the level of drinking in specific situations, (b) positive alcohol expectancies are hardly related to drinking measures, and negative alcohol expectancies primarily to more general indicators of drinking, (c) self-efficacy is moderately related to all drinking variables, (d) drinking motives do not act as mediator between positive alcohol expectancies and drinking because alcohol expectancies (independent variable) and drinking (dependent variable) were not directly significantly associated, and (e) no systematic moderator effects are apparent for age and gender concerning the associations between drinking cognitions and drinking.

\section{REFERENCES}

Aas, H. N., Leigh, B. C., Anderssen, N., \& Jakobsen, R. (1998). Two-year longitudinal study of alcohol expectancies and drinking among Norwegian adolescents. Addiction, 93, 373-384.

Aas, H., Klepp, K. I., Laberg, J. C., \& Edvard, L. (1995). Predicting adolescents' intentions to drink alcohol: Outcome expectancies and self-efficacy. Journal of Studies on Alcohol, 56, 293-299.

Abrams, D. B., \& Niaura, R. S. (1987). Social learning theory. In H. T. Blane \& K. E. Leonard (Eds.), Psychological theories of drinking and alcoholism (pp. 131-178). New York: Guilford Press.

Bandura, A. (Ed.). (1995). Self-efficacy in changing societies. New York: Cambridge University Press. 
Baron, R. M., \& Kenny, D. A. (1986). The moderator-mediator variable distinction in social psychological research: Conceptual, strategic, and statistical considerations. Journal of Personality and Social Psychology, 51, 1173-1182.

Bot, S. M., Engels, R. C. M. E., \& Knibble, R. A. (in press). Outcome expectancies and adolescent drinking: An observational study. Addiction.

Brown, S. A., Goldman, M. S., Inn, A., \& Anderson, L. R. (1980). Expectations of reinforcement from alcohol: Their domain and relation to drinking patterns. Journal of Consulting and Clinical Psychology, 48, 419-426.

Brown, S. A., Christiansen, B. A., \& Goldman, M. S. (1987). The alcohol expectancy questionnaire: An instrument for the assessment of adolescent and adult alcohol expectancies. Journal of Studies on Alcohol, 48, 483-491.

Christiansen, B. A., \& Goldman, M. S. (1983). Alcohol-related expectancies versus demographic/background variables in the prediction of adolescent drinking. Journal of Consulting and Clinical Psychology, 51, 249-257.

Connor, J. P., Young, R. McD., Williams, R. J., \& Ricciardelli, L. A. (2000). Drinking restraint versus alcohol expectancies: Which is the better indicator of alcohol problems? Journal of Studies on Alcohol, 61, 352-359.

Cooper, M. L. (1994). Motivations for alcohol use among adolescents: Development and validation of a four-factor model. Psychological Assessment, 6, 117-128.

Cooper, M. L., Frone, M. R., Russell, M., \& Mudar, P. (1995). Drinking to regulate positive and negative emotions: A motivational model of alcohol use. Journal of Personality and Social Psychology, 69, 990-1005.

Cooper, M. L., Russell, M., \& George, W. H. (1988). Coping, expectancies, and alcohol abuse: A test of social learning formulations. Journal of Abnormal Psychology, 97, 218-230.

Cox, W. M., \& Klinger, E. (1988). A motivational model of alcohol use. Journal of Abnormal Psychology, 97, 168-180.

De Vries, H., Dijkstra, M., \& Kuhlman, P. (1988). Self-efficacy: The third factor besides attitude and subjective norm as a predictor of behavioral intentions. Health Education Research, 3, 273-282.

Epstein, J. A., Griffin, K. W., \& Botvin, G. J. (2000). Role of general and specific competence skills in protecting inner-city adolescents from alcohol use. Journal of Studies on Alcohol, 61, 379-386.

Evans, D. M., \& Dunn, N. J. (1995). Alcohol expectancies, coping responses and selfefficacy judgments: A replication and extension of Cooper et al.'s 1988 study in a college sample. Journal of Studies on Alcohol, 56, 186-193.

George, W. H., Frone, M. R., Cooper, M. L., Russell, M., Skinner, J. B., \& Windle, M. (1995). A revised Alcohol Expectancy Questionnaire: Factor structure confirmation and invariance in a general population sample. Journal of Studies on Alcohol, 56, 177-185.

Goldman, M. S., Del Boca, F. K., \& Darkes, J. (1999). Alcohol expectancy theory: The application of cognitive neuroscience. In H. T. Blane \& K. E. Leonard (Eds.), Psychological theories of drinking and alcoholism (2nd ed.). The Guilford substance abuse series (pp. 203-246). New York: The Guilford Press.

Goldman, M. S., Greenbaum, P. E., \& Darkes, J. (1997). A confirmatory test of hierarchical expectancy structure and predictive power discriminant validation of the alcohol expectancy questionnaire. Psychological Assessment, 9, 145-157. 
Grunbaum, J. A., Tortolero, S., Weller, N., \& Gingiss, P. (2000). Cultural, social, and intrapersonal factors associated with substance use among alternative high school students. Addictive Behaviors, 25, 145-151.

Hajema, K. J. (1998). Sociological aspects of drinking behavior, alcohol-related problems and help-seeking. Dissertation. Maastricht: Datawyse.

Johnson, V. (1988). Adolescent alcohol and marijuana use: A longitudinal assessment of a social learning perspective. American Journal Drug Alcohol Abuse, 14, 419-439.

Jones , B. T., Corbin, W., \& Fromme, K. (2001). A review of expectancy theory and alcohol consumption. Addiction, 91, 57-72.

Lee, N. K., Oei, T. P. S., \& Greeley, J. D. (1999). The interaction of alcohol expectancies and drinking refusal self-efficacy in high and low risk drinkers. Addiction Research, 7, 91-102.

Leigh, B. C. (1989). In search of the seven dwarves: Issues of measurement and meaning in alcohol expectancy research. Psychological Bulletin, 105, 361-373.

Leigh, B. C., \& Stacy, A. W. (1993). Alcohol outcome expectancies: Scale construction and predictive utility in higher order confirmatory models. Psychological Assessment, 5, 216-229.

Lemmens, P., Tan, E. S., \& Knibbe, R. A. (1992). Measuring quantity and frequency of drinking in a general population survey: A comparison of five indices. Journal of Studies on Alcohol, 53, 476-486.

Mohr, C. D., Armeli, S., Tennen, H., Carney, M. A., Affleck, G., \& Hromi, A. (2001). Daily interpersonal experience, context, and alcohol consumption: Crying in your beer and toasting good times. Journal of Personality and Social Psychology, 80, 489-500.

Reese, F. L., Chassin, L., \& Molina, B. S. G. (1994). Alcohol expectancies in early adolescents: Predicting drinking behavior from alcohol expectancies and parental alcoholism. Journal of Studies on Alcohol, 55, 276-284.

Sher, K. J., Wood, M. D., Wood, P. K., \& Raskin, G. (1996). Alcohol outcome expectancies and alcohol use: A latent variable cross-lagged panel study. Journal of Abnormal Psychology, 105, 561-574.

Sher, K. J., \& Wood, M. D. (1997). Methodological issues in conducting prospective research on alcohol-related behavior: A report from the field. In K. J. Bryant, M. Windle, \& S. G. West (Eds.), The science of prevention. Washington, DC: American Psychological Association.

Smith, G. T., Goldman, M. S., Greenbaum, P. E., \& Christiansen, B. A. (1995). Expectancy for social facilitation from drinking: the divergent paths of high-expectancy and low-expectancy adolescents. Journal of Abnormal Psychology, 104, 32-40.

Sobell, L. C., \& Sobell, M. A. (1992). Timeline follow-back: A technique for assessing self-reported alcohol consumption. In R. Z. Litten \& J. P. Allen (Eds.), Measuring alcohol consumption: Psychosocial and biochemical methods (pp. 41-72). Totowa, NJ: Humana Press, Inc.

Stacy, A. W., Newcomb, M. D., \& Bentler, P. M. (1991). Cognitive motivation and drug use: A 9-year longitudinal study. Journal of Abnormal Psychology, 100, 502-515.

Stacy, A. W., Widaman, K. E., \& Marlatt, G. A. (1990). Expectancy models of alcohol use. Journal of Personality and Social Psychology, 58, 918-928. 
166 / ENGELS ET AL.

Stewart, S. H., Zeitlin, S. B., \& Samoluk, S. B. (1996). Examination of a three-dimensional drinking motives questionnaire in a young adult university student sample. Behaviour Research and Therapy, 34, 61-71.

Wechsler, H., Dowdall, G. W., Maenner, G., Gledhill-Hoyt, J., \& Lee, H. (1998). Changes in binge drinking and related problems among American college students between 1993 and 1997. Journal of American College Health, 47, 57-68.

Wiers, R. W., Gunning, W. B., \& Sergeant, J. A. (1998). Do young children of alcoholics hold more positive or negative alcohol-related expectancies than controls? Alcoholism: Clinical and Experimental Research, 22, 1855-1863.

Wiers, R. W., Hartgers, C. A., Van den Brink, W., Gunning, W. B., \& Sergeant, J. A. (2000). A confirmatory analysis of the hierarchical structure of positive and negative dose-related alcohol expectancies in alcoholics and the associations with family history of alcoholism. Journal of Studies on Alcohol, 61, 177-186.

Wiers, R. W., Hoogeveen, K. J., Sergeant, J. A., \& Gunning, W. B. (1997). High- and low-dose alcohol-related expectancies and the differential associations with drinking in male and female adolescents and young adults. Addiction, 92, 871-888.

Young, R. M., Oei, T. P., \& Crook, G. M. (1991). Development of a drinking self-efficacy questionnaire. Journal of Psychopathology and Behavioral Assessment, 13, 1-15.

Direct reprint requests to:

Rutger C. M. E. Engels

Behavioural Science Institute

Radboud University Nijmegen

P.O. Box 9104

6500 HE Nijmegen

The Netherlands

e-mail: R.Engels@bsi.ru.nl 